$\begin{array}{ll}\text { Abstracta Iranica } & \begin{array}{l}\text { Abstracta Iranica } \\ \text { Revue bibliographique pour le domaine irano-aryen }\end{array} \\ & \text { Volume } \mathbf{2 3} \mid \mathbf{2 0 0 2} \\ & \text { Comptes rendus des publications de } \mathbf{2 0 0 0}\end{array}$

\title{
Les jardins de solitude, nouvelles d'Iran. Paris, Les Mille et Une Nuits, 2000, 196 p.
}

\section{Christophe Balaÿ}

\section{(2) OpenEdition}

1 Journals

\section{Édition électronique}

URL : http://journals.openedition.org/abstractairanica/35880

DOI : 10.4000/abstractairanica.35880

ISSN : 1961-960X

Éditeur :

CNRS (UMR 7528 Mondes iraniens et indiens), Éditions de l'IFRI

\section{Édition imprimée}

Date de publication : 15 mai 2002

ISSN : 0240-8910

\section{Référence électronique}

Christophe Balaÿ, «Les jardins de solitude, nouvelles d'Iran. Paris, Les Mille et Une Nuits, 2000, 196 p. », Abstracta Iranica [En ligne], Volume 23 | 2002, document 315, mis en ligne le 08 février 2010, consulté le 25 septembre 2020. URL : http://journals.openedition.org/abstractairanica/35880 ; DOI : https:// doi.org/10.4000/abstractairanica.35880

Ce document a été généré automatiquement le 25 septembre 2020.

Tous droits réservés 


\title{
Les jardins de solitude, nouvelles d'Iran. Paris, Les Mille et Une Nuits, 2000, $196 \mathrm{p}$.
}

\author{
Christophe Balaÿ
}

1 A l'occasion du festival d'automne de Paris en l'an 2000, qui a fait une place particulière à la culture iranienne, S. Kasmaï, fascinée par l'ambivalence de l'imaginaire persan moderne, propose avec sept traductions de nouvelles, sept regards, sept climats. Parmi ces sept écrivains, la plupart vivent en dehors d'Iran, signe que la littérature persane n'est plus aujourd'hui une littérature lointaine mais qu'elle vit chez nous, en France, en Europe, souvent ignorée. Son passage dans la langue française, grâce à l'effort des sept traducteurs, ouvre notre horizon et l'élargit en nous invitant à ouvrir les yeux sur ce qui se passe ailleurs.

\section{INDEX}

Thèmes : 11.1.2. Littérature persane moderne

\section{AUTEURS}

CHRISTOPHE BALA $\ddot{Y}$

IFRI - Téhéran 